\title{
MicroRNA variants and colorectal cancer risk: a meta-analysis
}

X.M. Pan ${ }^{1 *}$, X. Xiao ${ }^{2 *}$, H.J. Qin ${ }^{1}$, Z. Zhang ${ }^{1}$, Z.H. Li ${ }^{3}$, L.B. Gao ${ }^{4}$ and J. Jia ${ }^{5}$

${ }^{1}$ Department of Forensic Pathology,

Henan University of Science and Technology, Luoyang, Henan, China

${ }^{2}$ Department of Obstetrics and Gynecology,

West China Second University Hospital, Sichuan University, Chengdu, Sichuan, China

${ }^{3}$ Secondary Department of General Surgery,

Luoyang Central Hospital Affiliated to Zhengzhou University, Luoyang, Henan, China

${ }^{4}$ Laboratory of Molecular and Translational Medicine,

West China Institute of Women and Children's Health,

West China Second University Hospital, Sichuan University,

Chengdu, Sichuan, China

${ }^{5}$ Center for Molecular Medicine, Zhejiang Academy of Medical Sciences,

Hangzhou, Zhejiang, China

*These authors contributed equally to this study.

Corresponding author: J. Jia

E-mail: ann_nance@sina.com.cn

Genet. Mol. Res. 15 (3): gmr.15038478

Received January 25, 2016

Accepted June 14, 2016

Published August 29, 2016

DOI http://dx.doi.org/10.4238/gmr.15038478

Copyright $(2016$ The Authors. This is an open-access article distributed under the terms of the Creative Commons Attribution ShareAlike (CC BY-SA) 4.0 License

ABSTRACT. Colorectal cancer (CRC) is a multi-factorial disease, and
genetic background may contribute to its etiology. Single nucleotide
polymorphisms (SNPs) in microRNAs (miRNAs) may be used as
specific markers of predisposition for CRC diagnosis and prevention.

Genetics and Molecular Research 15 (3): gmr.15038478 
In this review, we summarize and discuss recent publications evaluating the roles of miRNA SNPs in CRC. A meta-analysis was also carried out to assess the association between the five most frequently studied miRNA SNPs and CRC risk. No relationship was established between this disease and the three SNPs rs11614913, rs2910164, and rs3746444 in miR-196a-2, miR-146a, and miR-499, respectively. However, polymorphisms of miR-149 (rs2292832; CT vs TT: odds ratio [OR] = $0.816,95 \%$ confidence interval $[\mathrm{CI}]=0.691-0.963 ; \mathrm{CC}+\mathrm{CT}$ vs TT: OR $=0.834,95 \% \mathrm{CI}=0.715-0.972)$ and pre-miR-27a (rs895819; GG vs AA: $\mathrm{OR}=1.534,95 \% \mathrm{CI}=1.148-2.049 ; \mathrm{GG}+\mathrm{AG} v s \mathrm{AA}: \mathrm{OR}=1.324$, $95 \% \mathrm{CI}=1.066-1.645)$ were found to be associated with CRC in our analysis. In conclusion, the SNPs rs 2292832 in miR-149 and rs895819 in pre-miR-27a were associated with CRC susceptibility, whereas rs11614913, rs2910164, and rs3746444 in miR-196a-2, miR-146a, and miR-499, respectively, were not. Further studies should be carried out to validate these findings.

Key words: MicroRNA; Single nucleotide polymorphism; Colorectal cancer; Review; Meta-analysis

\section{INTRODUCTION}

Colorectal cancer (CRC) is the third most frequently diagnosed malignancy in men and the second among women. In 2012, approximately 1.4 million cases were diagnosed, and 693,900 CRC-related deaths occurred (Torre et al., 2015). In China, an estimated 310,244 cases and 149,722 deaths were recorded in 2011, placing CRC among the top five malignancies for incidence and mortality (Chen et al., 2015). To date, the exact mechanisms responsible remain obscure, and efficient diagnostic methods and treatments for this disease are lacking. Thus, there exists an urgent need to develop new strategies to diagnose and target individuals at high risk of CRC.

$\mathrm{CRC}$ is a multi-factorial disease. Genetic background, environmental factors, and gene-environment interactions all contribute to its etiology. Many studies have been carried out to identify genetic variations that might be used for CRC diagnosis and prognostic assessment. Two single nucleotide polymorphisms (SNPs) in miR-608 and miR-219-1 are reported to be associated with CRC survival and recurrence, and thus might be useful in predicting therapy response (Pardini et al., 2015). In addition, a microarray analysis of $146 \mathrm{CRC}$ cases revealed that the rs6707530 SNP in the fibronectin 1 gene may be helpful in diagnosing this condition (Kida et al., 2014). Zhi et al. (2015) also reported serum miR-29a level to be a promising CRC biomarker, with a diagnostic specificity of 0.89 .

MicroRNAs (miRNAs) are small, non-coding, single-stranded RNAs of 21-24 nucleotides capable of binding complementary sequences within target mRNAs for posttranscriptional regulation of their functions as tumor suppressors or oncogenes. SNPs are common variants in the human genome and have been reported to influence disease susceptibility. SNPs in miRNAs may alter miRNA processing or expression, or influence mRNA function, potentially contributing to cancer susceptibility. Therefore, miRNA polymorphisms may be used as specific markers of predisposition for CRC diagnosis and prevention.

Genetics and Molecular Research 15 (3): gmr.15038478 
To date, several reviews analyzing the relationship between miRNA polymorphisms and cancer risk have been published (Du et al., 2013; Xie et al., 2014). However, these articles have focused on only one or a small number of selected miRNA SNPs. A comprehensive analysis of all reported CRC-related miRNAs is lacking. In this review, we aimed to assemble an extensive list of all miRNA SNPs with potential roles in CRC, carry out a meta-analysis of the most frequently studied miRNAs, and discuss the underlying mechanisms by which such polymorphisms affect CRC susceptibility.

\section{Differentially expressed miRNAs in CRC}

Accumulating evidence strongly indicates that aberrant miRNA expression is an important feature of CRC. A recent study measured the differential expression of miRNAs in colorectal adenocarcinoma tissues from 28 patients, and analyzed their profiles at various differentiation stages. The levels of 1547 miRNAs were detected by quantitative real-time polymerase chain reaction, 93 of which were found to be significantly dysregulated in these malignant tissues. In particular, miR-1, miR-145, and miR-145* were shown by receiver operating characteristic analysis to be potential biomarkers for CRC diagnosis. Furthermore, 58 miRNAs demonstrated significantly altered expression between well- and moderately differentiated cancers, and 32 could be used to distinguish normal from cancerous tissues, as well as different levels of differentiation (Wu et al., 2015). Gu et al. (2014) proposed a gene module-based approach to infer the identity of key miRNAs involved in CRC. miR-101, miR-124, and miR-139 were found to be frequently down-regulated in this disease, and using this approach, the latter was determined to be a key tumor suppressor in early cancer development. Using a microarray, Yong et al. (2013) identified seven miRNAs differentially expressed in both CRC tissue and blood samples, and indicated that the triple miRNA classifier comprising miR-193a-3p, miR-23a, and miR-338-5p is a potential blood biomarker for early CRC detection. According to various miRNA-profiling studies, several miRNAs have been validated as potential oncogenes or tumor suppressor genes in CRC. SNPs in miRNAs and related loci are often located in miRNA primary (pri-) and precursor (pre-) sequences, seed sequences, and the 3'-untranslated regions of target genes (Landi et al., 2012). Thus, such polymorphisms might influence miRNA function in three ways: by altering transcription of the primary transcript, affecting pri- and pre-miRNA processing, and modifying miRNA-miRNA interactions (Ryan et al., 2010). SNPs in miRNAs may ultimately result in the alteration of their expression and/or maturation, with possible consequences for cancer development and progression. Furthermore, approximately half of miRNA genes are located in cancer-related regions (Garzon et al., 2010). Thus, variations in these sequences may result in significant functional consequences, making them ideal candidates for cancer risk prediction. Many have been validated as potential oncogenes or tumor suppressor genes in CRC, such as miR-143, miR-145, miR-21, and miR200c (Schetter and Harris, 2011). miRNA expression profile analyses indicate that these sequences play an etiological role in the initiation and progression of this condition. Therefore, the study of miRNAs may provide a better understanding of the molecular mechanisms responsible for CRC pathology, and assist in the development of CRC diagnosis and treatment approaches.

\section{miRNA SNPs and their association with CRC}

SNPs in miRNAs can affect hundreds of mRNAs, since it is estimated that mature

Genetics and Molecular Research 15 (3): gmr.15038478 
miRNAs regulate around $30 \%$ of human genes. Since the first report of their existence, several studies have been carried out to identify these variants and explore their associations with cancer.

Recently, numerous miRNA sequence variations have been implicated in CRC ( $\mathrm{Lv}$ et al., 2013; Cao et al., 2014). However, the results of many such studies are conflicting and inconclusive. In the present study, we focused on the relationship between miRNA polymorphisms and CRC. A systematic review was carried out to comprehensively analyze and integrate all published studies concerning miRNA SNPs in relation to CRC risk.

\section{MATERIAL AND METHODS}

\section{Selection of published studies}

We searched the PubMed database (most recently on June 30, 2015) for all articles relevant to the association between miRNA SNPs and CRC. The following search terms were used: "miRNA polymorphism, miRNA SNP, or miRNA variant" and "colorectal cancer or colorectal tumor". Additional eligible studies were identified by a manual search of the references included in retrieved articles (Figure 1). Authors of the selected papers were not contacted.

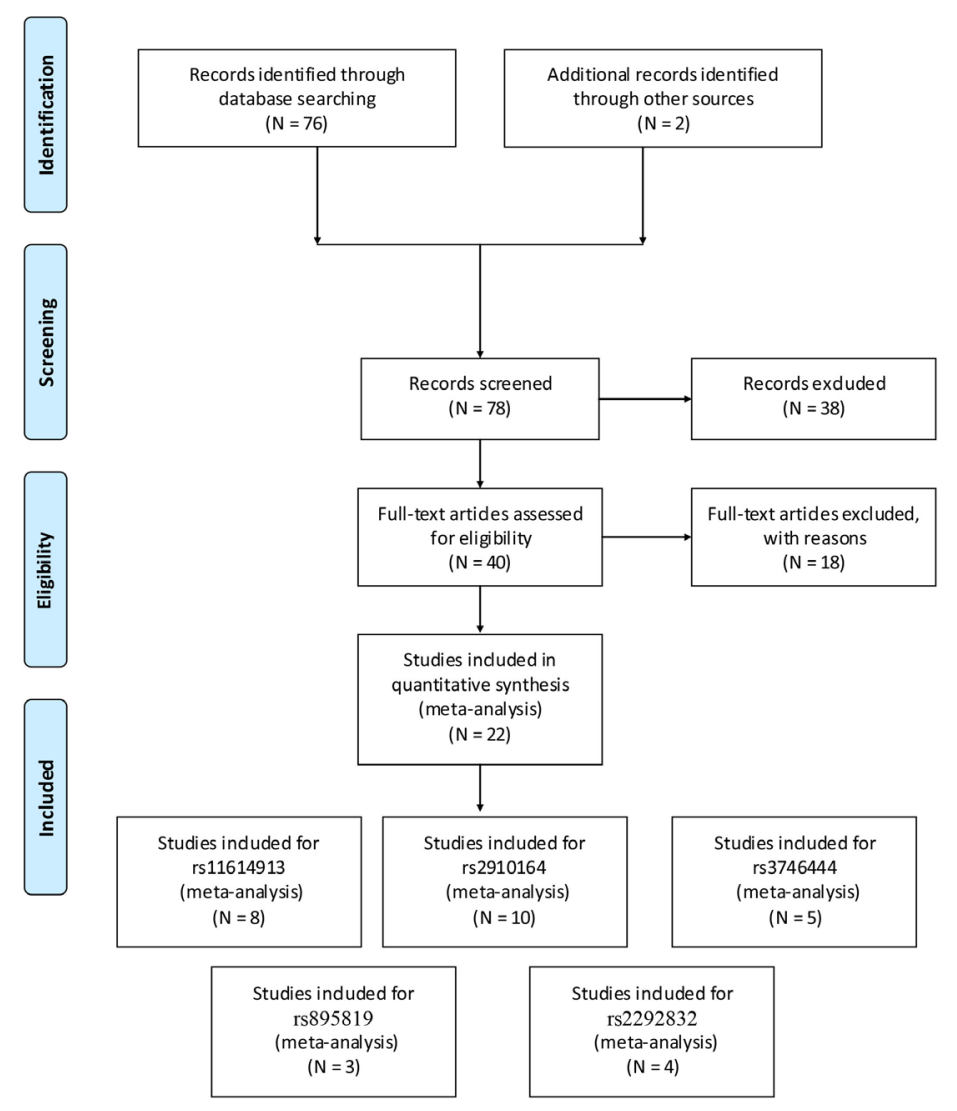

Figure 1. Flow diagram of the study inclusion process.

Genetics and Molecular Research 15 (3): gmr.15038478 


\section{Inclusion and exclusion criteria}

Studies testing the association between miRNA polymorphisms and CRC were included if all of the following conditions were met: a) the investigation consisted of a casecontrol design; b) the total number of cases and controls was made available; c) genotype frequencies in case and control groups were given; and d) the study was published in English. The principal exclusion criteria were as follows: a) data for calculation of odds ratios (ORs) was lacking and b) the retrieved document consisted of an abstract, comment or editorial.

A total of 78 relevant articles were identified finally. After screening of titles and abstracts, 38 studies clearly irrelevant to the subject of interest were excluded, and from the remaining 40 publications, 18 reviews were removed. Finally, after screening of method sections, 22 epidemiological investigations focusing on the importance of miRNA-related SNPs in CRC susceptibility were retained [Zhan et al., 2011; Chen et al., 2012; Hezova et al., 2012; Min et al., 2012; Ryan et al., 2012; Zhang et al., 2012; Zhu et al., 2012; Chae et al., 2013; Gao et al., 2013; Lv et al., 2013; Ma et al., 2013; Vinci et al., 2013; Cao et al., 2014; Hu et al., 2014; Li et al., 2013, 2014 (for unpublished results of Chen, 2013); Mao et al., 2014; Oh et al., 2014; Parlayan et al., 2014; Wang et al., 2014a,b; Dikaiakos et al., 2015; Table 1], including data from two unpublished studies extracted from review articles.

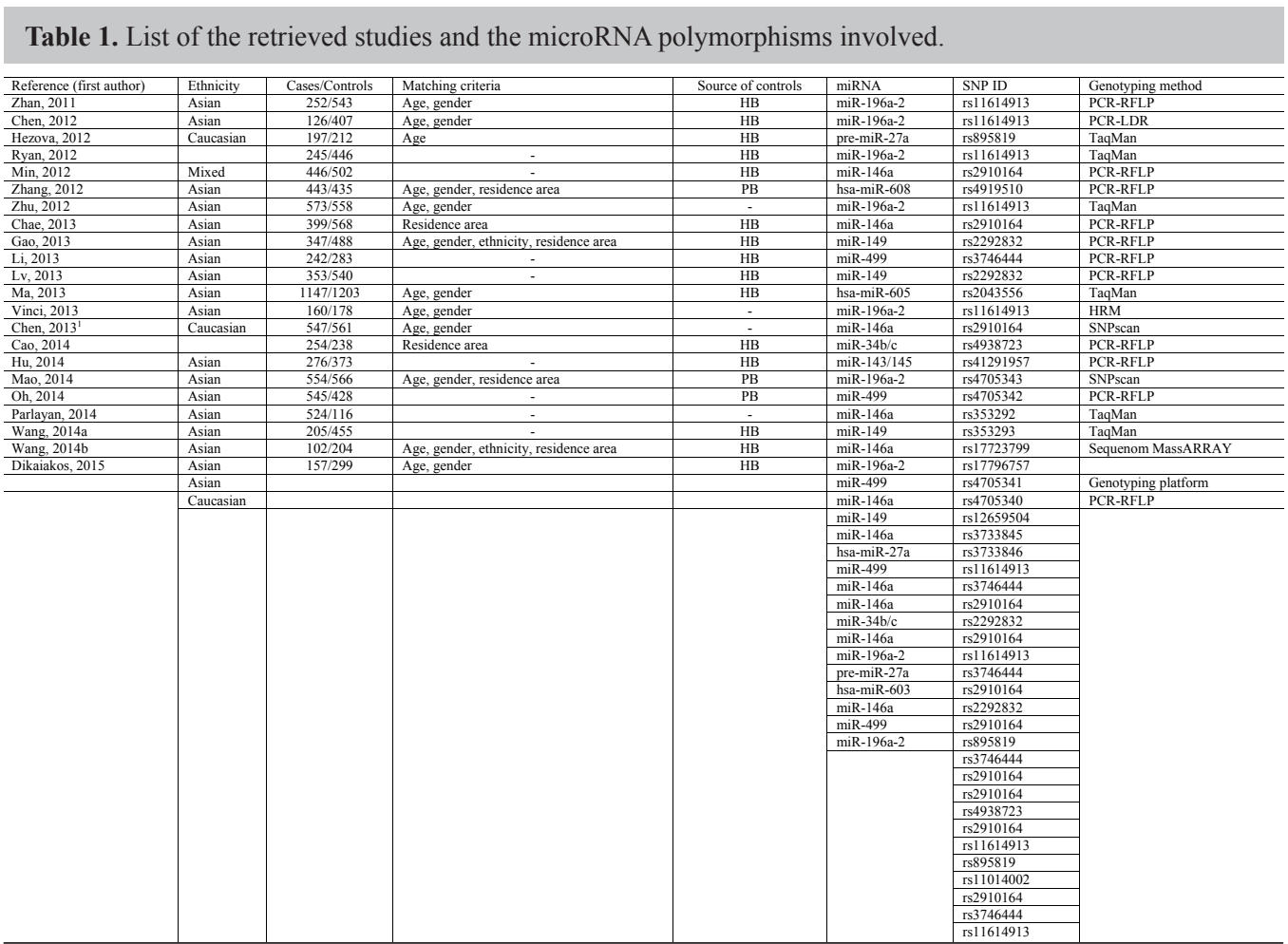

miRNA = microRNA; SNP = single nucleotide polymorphism; HB = hospital-based study; PB = populationbased study; PCR-RFLP = polymerase chain reaction-restriction fragment length polymorphism; PCR-LDR = polymerase chain reaction-ligase detection reaction; $\mathrm{HRM}=$ high-resolution melting. ${ }^{1}$ Unpublished data recorded by Chen (2013), included in the review authored by Li et al. (2014).

Genetics and Molecular Research 15 (3): gmr.15038478 


\section{Quality assessment}

The Newcastle-Ottawa Scale was used for quality assessment. Quality was judged based on three aspects of each case-control study: selection, comparability, and exposure. A "star" rating system was used, with scores ranging from 0 to 9 . We assessed the quality

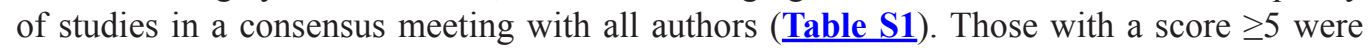
considered to be of high quality.

\section{Data extraction}

Two researchers independently extracted data from each document using a predefined review form, and discrepancies were resolved by consensus among all investigators. The following information was recorded for each study: first author, year of publication, miRNA name, SNP ID, ethnicity of participants, number of cases and controls, genotyping method, matching criteria, source of controls, minor allele frequency among controls, and conformity to Hardy-Weinberg equilibrium (HWE; Table 1). Ethnicity was categorized as Asian, Caucasian, or mixed. However, no subgroup analysis by population was carried out, as the focus of the present study was on the relationship between miRNA polymorphisms and CRC risk in the overall patient group.

A list of the miRNA SNPs evaluated in regard to CRC is shown in Table 1. The most frequently studied of these were rs11614913 (miR-196a-2), rs2910164 (miR-146a), rs3746444 (miR-499), rs2292832 (miR-149), and rs895819 (pre-miR-27a).

\section{Statistical analysis}

Deviation from HWE in the control group was examined by the chi-square test, and $\mathrm{P}<0.05$ was considered statistically significant. The strength of relationships between miRNA polymorphisms and CRC risk was assessed using pooled ORs with $95 \%$ confidence intervals (CIs). Risk was estimated using allelic, homozygous, heterozygous, dominant, and recessive models. Heterogeneity was assessed with the chi-square-based $Q$-statistic. When this test returned $\mathrm{P}$ values $<0.05$, a random-effect model was applied (the DerSimonian and Laird method); otherwise, a fixed-effect model was employed (the Mantel-Haenszel method). Funnel plots and Egger's linear regression method were used to detect potential publication bias, and sensitivity analyses were performed to assess the stability of the results. All tests were performed with the Stata software, version 10.0 (StataCorp., College Station, TX, USA). All P values were two-sided.

\section{RESULTS}

Twenty-two case-control studies were included in this review. Most of these had NOS scores of 5, and all were of high quality in terms of selection and exposure (Table S1). Only the previously unpublished data recorded by Chen (2013), included in the review authored by Li et al. (2014), scored 4 stars, owing to a lack of information regarding experimental design.

In the following section, we discuss the SNPs rs11614913 (miR-196a-2), rs2910164 (miR-146a), rs3746444 (miR-499), rs2292832 (miR-149), and rs895819 (pre-miR-27a), and

Genetics and Molecular Research 15 (3): gmr.15038478 
present our meta-analysis evaluating the association between each of these and $\mathrm{CRC}$ risk. The relationship between this disease and other less frequently studied SNPs is also considered. We did not adjust our results for environmental effects, as our investigation concentrated on the influence of genetics on cancer development, nor did we carry out subgroup analyses.

\section{DISCUSSION}

\section{rs11614913 in miR-196a-2 and its association with CRC}

The rs11614913 polymorphism in miR-196a-2 has been associated with susceptibility to various cancers. The molecular basis for this remains obscure; however, it has been speculated that the $\mathrm{T}$ to $\mathrm{C}$ mutation in the pre-miRNA stem region may alter the expression level of mature miR-196a-2 and influence its binding to target mRNA (Hoffman et al., 2009). As elevated expression of miR-196a (the mature miRNA encoded by miR196a-2 gene) can promote CRC cell migration and invasion, sequence variations leading to such increased transcription might raise CRC risk (Guo et al., 2012). We retrieved nine studies concerning the association between rs11614913 and this disease (Table 2). Three of these reported that the TC genotype increased CRC risk compared to the TT genotype, whereas three others demonstrated that it decreased susceptibility. Six studies showed individuals with the $\mathrm{CC}$ genotype to be at increased risk in comparison to those with the TT genotype, and one investigation established the opposite effect. Taking the CC genotype as a reference, Lv et al. (2013) and Vinci et al. (2013) obtained entirely different results. However, in a study of CRC tissues, Zhan et al. (2011) reported that miR-196a expression is significantly higher in patients carrying CC or TC genotypes than in TT carriers. In our meta-analysis of the association between this miR-196a-2 polymorphism and CRC risk, eight studies comprising 2264 cases and 3199 controls were included (Parlayan's study was excluded because the genotype distribution data of control is lacking). We found no relationship between rs11614913 and CRC under any genetic model (CC vs TT: OR $=0.852$, $95 \% \mathrm{CI}=0.479-1.515 ; \mathrm{CT}$ vs $\mathrm{TT}: \mathrm{OR}=0.946,95 \% \mathrm{CI}=0.735-1.216 ; \mathrm{CC}+\mathrm{CT}$ vs $\mathrm{TT}: \mathrm{OR}=$ $0.945,95 \% \mathrm{CI}=0.689-1.298 ; \mathrm{C} v s \mathrm{~T}: \mathrm{OR}=0.962,95 \% \mathrm{CI}=0.752-1.230)$.

\begin{tabular}{|c|c|c|c|c|c|c|c|c|}
\hline \multirow[t]{2}{*}{ Reference (first author) } & \multirow[t]{2}{*}{ Nation } & \multirow[t]{2}{*}{ Sample size (cases/ controls) } & \multicolumn{3}{|c|}{ Genotype distribution (cases/controls) } & \multirow{2}{*}{$\begin{array}{c}\text { Callele frequency } \\
\text { (controls) }\end{array}$} & \multirow[t]{2}{*}{ Risk in original publication [OR $(95 \% \mathrm{CI})]$} & \multirow{2}{*}{$\begin{array}{c}\mathrm{HWE} \\
\mathrm{P} \text { value }\end{array}$} \\
\hline & & & TT & $\mathrm{TC}$ & $\mathrm{CC}$ & & & \\
\hline Zhan, 2011 & China & $252 / 543$ & $56 / 163$ & $128 / 263$ & $68 / 113$ & 0.453618 & TC/TT: $1.394(0.947-2.052)$ & 0.716 \\
\hline Chen, 2012 & China & $126 / 407$ & $35 / 107$ & $64 / 206$ & $27 / 94$ & 0.484029 & \begin{tabular}{|l} 
CC/TT: $1.743(1.112-2.731)$ \\
\end{tabular} & 0.788 \\
\hline Hezova, 2012 & Czech Republic & $197 / 212$ & $82 / 87$ & $89 / 103$ & $26 / 22$ & 0.346698 & TC/TT: $1.053(0.656-1.691)$ & 0.291 \\
\hline Min, 2012 & Korea & $446 / 502$ & $125 / 148$ & $201 / 254$ & $120 / 100$ & 0.452191 & CC/TT: $1.139(0.642-2.021)$ & 0.633 \\
\hline Zhu, 2012 & China & $573 / 558$ & $130 / 172$ & $303 / 295$ & $140 / 121$ & 0.456633 & TC/TT: $0.95(0.62-1.45)$ & 0.790 \\
\hline $\mathrm{Lv}, 2013$ & China & $353 / 540$ & $114 / 91$ & $223 / 331$ & $10 / 109$ & 0.483051 & CC/TT: $1.32(0.69-2.54)$ & $<0.05$ \\
\hline Vinci, 2013 & Italy & $160 / 178$ & $12 / 11$ & $86 / 84$ & $62 / 83$ & 0.297753 & TC/TT: $0.94(0.69-1.27)$ & 0.087 \\
\hline Parlayan, 2014 & Japan & $524 / 116$ & $43 /--$ & $59 /--$ & $23 /--$ & NA & CC/TT: $1.42(0.99-2.03)$ & 0.156 \\
\hline \multirow{9}{*}{ Dikaiakos, 2015} & Greece & $157 / 299$ & $69 / 117$ & $69 / 149$ & $19 / 33$ & 0.359532 & TC/TT: $1.36(1.03-1.80)$ & \\
\hline & & & & & & & 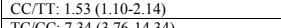 & \\
\hline & & & & & & & \begin{tabular}{|l|} 
TC/CC: $7.34(3.76-14.34)$ \\
TT/2.6.7.7.
\end{tabular} & \\
\hline & & & & & & & \begin{tabular}{|l|} 
TT/CC: $13.66(6.76-27.6)$ \\
TC.
\end{tabular} & \\
\hline & & & & & & & \begin{tabular}{|l|} 
TC/CC: $0.721(0.46-1.13)$ \\
TC
\end{tabular} & \\
\hline & & & & & & & \begin{tabular}{|l|} 
TT/CC: $0.587(0.25-1.38)$ \\
T/
\end{tabular} & \\
\hline & & & & & & & & \\
\hline & & & & & & & \begin{tabular}{|l|l|} 
TC/TT: $0.78(0.52-1.86)$ \\
\end{tabular} & \\
\hline & & & & & & & CC/TT: $0.98(0.51-1.85)$ & \\
\hline \multirow[t]{3}{*}{ Overall } & & $2264 / 3199$ & & & & & \multirow{2}{*}{\multicolumn{2}{|c|}{\begin{tabular}{|l|} 
CC/TT: $0.852(0.479-1.515) ;$ P: 0.585 \\
CT/TT: $0.946(0.735-1.216) ; P: 0.664$
\end{tabular}}} \\
\hline & & & & & & & & \\
\hline & & & & & & & \begin{tabular}{|l|} 
CC+CT/TT: $0.945(0.689-1.298) ; \mathrm{P}: 0.728$ \\
CT: $0.962(0.752-1.230): P \cdot 0.758$ \\
\end{tabular} & \\
\hline
\end{tabular}

$\mathrm{OR}=$ odds ratio $\mathrm{CI}=$ confidence interval $\mathrm{HWE}=$ Hardy-Weinberg equilibrium; $\mathrm{NA}=$ not applicable. 


\section{rs2910164 in miR-146a and its association with CRC}

miR-146a was first identified in mice, and plays a crucial role in tumorigenesis by promoting cell proliferation and colony formation. Its deregulation has been reported in tumor tissue in several studies, implying a tumor-suppressor function, and it has also been shown to suppress metastasis. The rs $2910164 \mathrm{G}>\mathrm{C}$ polymorphism at position +60 of the gene encoding miR-146a results in a G:U to $C: U$ leader sequence change, causing a base-pair mismatch (Chae et al., 2013). The $\mathrm{C}$ allele leads to a less stable secondary structure and decreased production of mature miR-146a (Li et al., 2010). This SNP has been associated with a variety of cancers. We collated 11 studies testing the association between rs2910164 and CRC (Table 3 ); however, their results were conflicting. Compared to the GG genotype, five investigations supported a link between the GC genotype and decreased CRC risk, while three found it to increase susceptibility. Seven studies suggested that the CC genotype lowered the likelihood of developing CRC compared to the GG genotype, whereas two suggested that it raised this risk. In our meta-analysis evaluating the link between this miR-146a polymorphism and CRC, 10 studies were included, representing 4236 cases and 5002 controls. We failed to detect a correlation between rs2910164 and CRC under any of the genetic models tested (CC vs GG: $\mathrm{OR}=0.986,95 \% \mathrm{CI}=0.778-1.250 ; \mathrm{GC} v s \mathrm{GG}: \mathrm{OR}=1.002,95 \% \mathrm{CI}=0.823-1.221 ; \mathrm{CC}+\mathrm{GC} v s$ GG: $\mathrm{OR}=0.995,95 \% \mathrm{CI}=0.831-1.192 ; \mathrm{C} v \mathrm{~S}: \mathrm{OR}=0.969,95 \% \mathrm{CI}=0.864-1.086$ ).

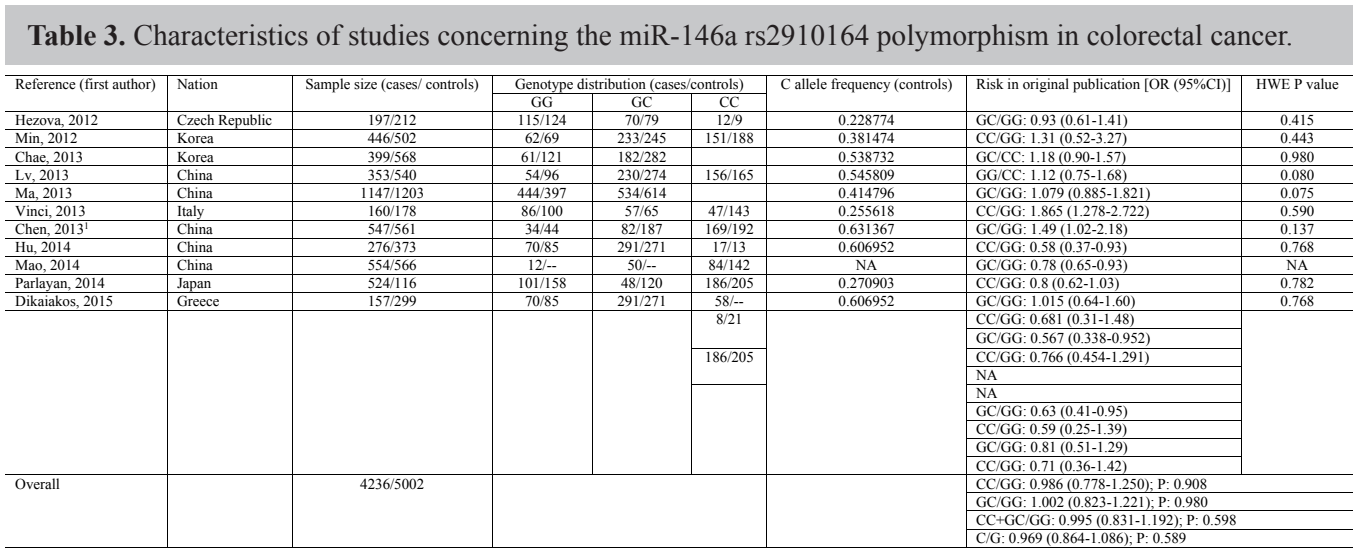

$\overline{\mathrm{OR}}=$ odds ratio $\mathrm{CI}=$ confidence interval $; \mathrm{HWE}=$ Hardy-Weinberg equilibrium; $\mathrm{NA}=$ not applicable. ${ }^{1}$ Unpublished data recorded by Chen (2013), included in the review authored by Li et al. (2014).

\section{rs3746444 in miR-499 and its association with CRC}

rs3746444 is an important SNP located in the seed sequence (nucleotides 2-8) of hsa-miR-499, consisting of an A to G base change (Akkiz et al., 2011). The seed region at the 5'-end of this sequence is important for miRNA-miRNA binding, thus the rs 3746444 polymorphism might affect interactions between miR-499 and other miRNAs to influence cancer susceptibility. We identified five studies regarding the association between this SNP and CRC (Table 4), with contradictory results. Three of these asserted that the GG genotype decreased CRC risk compared to the AA genotype, while three proposed that the AG 
genotype increased susceptibility, also in comparison to the AA genotype. Five investigations, consisting of 1392 cases and 1892 controls, were included in our meta-analysis, which found no association between rs3746444 and CRC risk using any genetic model (AG vs AA: OR = $1.011,95 \% \mathrm{CI}=0.862-1.185 ; \mathrm{GG} v s \mathrm{AA}: \mathrm{OR}=1.022,95 \% \mathrm{CI}=0.783-1.335 ; \mathrm{GG}+\mathrm{AG} v s \mathrm{AA}$ : $\mathrm{OR}=1.019,95 \% \mathrm{CI}=0.811-1.179 ; \mathrm{C} v s \mathrm{G}: \mathrm{OR}=1.023,95 \% \mathrm{CI}=0.908-1.154)$.

Table 4. Characteristics of studies concerning the miR-499 rs3746444 polymorphism in colorectal cancer.

\begin{tabular}{|c|c|c|c|c|c|c|c|c|}
\hline Reference (first author) & Nation & $\begin{array}{l}\text { Sample size (cases/ controls) } \\
\end{array}$ & 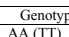 & $\begin{array}{l}\text { distribution } \\
\text { AGG(TC) }\end{array}$ & $\frac{\text { ases/controls) }}{\mathrm{GG}(\mathrm{CC})}$ & $\begin{array}{l}\mathrm{G} \text { (C) allele frequency (controls) } \\
\end{array}$ & Risk in original publication [OR $\left.\left(95^{\circ} \% \mathrm{Cl}\right)\right]$ & HWE P value \\
\hline \begin{tabular}{|l|l} 
Min, 2012 \\
Lv 2013
\end{tabular} & \begin{tabular}{|l} 
Korea \\
China
\end{tabular} & $\frac{446502}{353540}$ & $\begin{array}{l}292 / 334 \\
2583366\end{array}$ & $\frac{142 / 154}{881 / 138}$ & $\begin{array}{l}12 / 14 \\
5496 \\
\end{array}$ & $\begin{array}{ll}0.181 \\
0.275\end{array}$ & $\begin{array}{l}\text { AG/AA: } 1.06(0.80-1.39) \\
\text { GG/AA: } 099(0.54-15)\end{array}$ & $\begin{array}{l}0.453 \\
<005 \\
\end{array}$ \\
\hline Vinci, 2013 & $\begin{array}{c}\text { Chmaly } \\
\text { Italy }\end{array}$ & $\frac{353 / 540}{160 / 178}$ & $\begin{array}{lll}203500 \\
93 / 105\end{array}$ & $\frac{88178}{32 / 56}$ & 35/17 & 0.275 & & $<0.05$ \\
\hline & & & & & & & $\mathrm{AG} / \mathrm{AA} \cdot 0663(0.39-1.11 \mathrm{~d}$ & $\frac{0.03}{0.162}$ \\
\hline Dikaiakos, 2015 & Greece & $157 / 299$ & $85 / 182$ & $64 / 99$ & $8 / 18$ & 0.226 & GG/AA: $2.931(1.49-5.77)$ & \\
\hline & & & & & & & 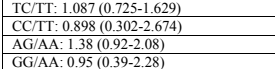 & \\
\hline Overall & & $1392 / 1892$ & & & & & 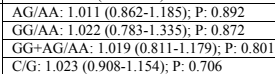 & \\
\hline
\end{tabular}

$\mathrm{OR}=$ odds ratio; $\mathrm{CI}=$ confidence interval; $\mathrm{HWE}=$ Hardy-Weinberg equilibrium; $\mathrm{NA}=$ not applicable.

\section{rs895819 in pre-miR-27a and rs2292832 in miR-149}

The gene encoding miR-27a has been reported to be involved in the development of gastrointestinal cancer. rs 895819 is located at position +40 relative to the first nucleotide of miR-27a. This A to G mutation has been shown to increase miR-27a expression in tumor tissues (Cao et al., 2014). We examined three publications, involving 656 cases and 905 controls (Table 5). Only one study indicated that the AG genotype increased CRC risk compared to the AA genotype, with two demonstrating that the GG genotype elevates susceptibility. Our metaanalysis showed that rs 895819 does increase $\mathrm{CRC}$ risk under homozygous (GG vs AA: OR $=$ $1.534,95 \% \mathrm{CI}=1.148-2.049, \mathrm{P}=0.004)$, dominant $(\mathrm{GG}+\mathrm{AG} v \mathrm{AA}: \mathrm{OR}=1.324,95 \% \mathrm{CI}=$ $1.066-1.645, \mathrm{P}=0.011)$, and allelic models $(\mathrm{C} v s \mathrm{G}: \mathrm{OR}=1.280,95 \% \mathrm{CI}=1.102-1.486, \mathrm{P}=$ 0.001 ), but not under the heterozygous model ( $\mathrm{AG} v s \mathrm{AA}: \mathrm{OR}=1.230,95 \% \mathrm{CI}=0.971-1.558$, $\mathrm{P}=0.087)$.

Table 5. Characteristics of studies concerning the pre-miR-27a rs 895819 polymorphism in colorectal cancer.

\begin{tabular}{|c|c|c|c|c|c|c|c|c|}
\hline \multirow[t]{2}{*}{ Reference (first author) } & \multirow[t]{2}{*}{ Nation } & \multirow[t]{2}{*}{ Sample size (cases/ controls) } & \multicolumn{3}{|c|}{$\begin{array}{l}\text { Genotype distribution } \\
\text { (cases/controls) }\end{array}$} & \multirow[t]{2}{*}{$\begin{array}{l}\mathrm{C} \text { allele frequency } \\
\text { (controls) }\end{array}$} & \multirow[t]{2}{*}{ Risk in original publication $[\mathrm{OR}(95 \% \mathrm{CI})]$} & \multirow[t]{2}{*}{ HWE P value } \\
\hline & & & $\mathrm{AA}$ & $\mathrm{AG}$ & GG & & & \\
\hline Hezova, 2012 & Czech Republic & $197 / 212$ & $88 / 93$ & $86 / 94$ & $23 / 25$ & 0.340 & AG/AA: $0.98(0.64-1.49)$ & 0.867 \\
\hline Cao, 2014 & China & $254 / 238$ & $92 / 114$ & $113 / 93$ & $49 / 31$ & 0.326 & GG/AA: $1.04(0.54-1.98)$ & 0.089 \\
\hline \multirow{4}{*}{ Wang, 2014a } & China & $205 / 455$ & $48 / 138$ & $68 / 157$ & $89 / 160$ & 0.524 & AG/AA: $1.506(1.021-2.220)$ & $<0.05$ \\
\hline & & & & & & & GG/AA: $1.959(1.156-3.318)$ & \\
\hline & & & & & & & $\mathrm{AG} / \mathrm{AA}: 1.245(0.806-1.923)$ & \\
\hline & & & & & & & GG/AA: $1.865(1.052-2.430)$ & \\
\hline \multirow[t]{3}{*}{ Overall } & & $656 / 905$ & & & & & \multicolumn{2}{|l|}{ GG/AA: $1.534(1.148-2.049) ;$ P: 0.004} \\
\hline & & & & & & & \multirow{2}{*}{\multicolumn{2}{|c|}{$\begin{array}{l}\text { GG+AG/AA: } 1.324(1.066-1.645) ; P: 0.011 \\
\text { C/G: } 1.280 \text { (1.102-1.486); P: } 0.001\end{array}$}} \\
\hline & & & & & & & & \\
\hline
\end{tabular}

$\mathrm{OR}=$ odds ratio $\mathrm{CI}=$ confidence interval HWE $=$ Hardy-Weinberg equilibrium .

miR-149 has been described as both a tumor suppressor and an oncogene in the development of various tumors (Zhang et al., 2012). Use of real-time polymerase chain reaction has revealed that miR-149 mRNA levels are increased in the tumor tissues of patients carrying rs $2292832 \mathrm{CC}$ or CT genotypes. We retrieved four articles, including a total of 1402 
cases and 1655 controls (Table 6). None of these studies established an association between this polymorphism and CRC risk. However, our meta-analysis of this relationship suggested that rs2292832 might decrease CRC risk under heterozygous (CT vs TT: $\mathrm{OR}=0.816,95 \% \mathrm{CI}$ $=0.691-0.963)$ and dominant models $(\mathrm{CC}+\mathrm{CT}$ vs TT: $\mathrm{OR}=0.834,95 \% \mathrm{CI}=0.715-0.972)$, but not under allelic $(\mathrm{C} v s \mathrm{~T}$ : $\mathrm{OR}=0.906,95 \% \mathrm{CI}=0.809-1.015)$ or homozygous models $(\mathrm{CC} v s$ TT: $\mathrm{OR}=0.885,95 \% \mathrm{CI}=0.693-1.130)$.

Table 6. Characteristics of studies concerning the miR-149 rs2292832 polymorphism in colorectal cancer.

\begin{tabular}{|c|c|c|c|c|c|c|c|c|}
\hline Reference (first author) & Nation & Sample size (cases/ controls) & Genotyp & distributio & ses/controls) & C allele frequency (controls) & \begin{tabular}{|l|} 
Risk in original publication [OR $(95 \% \mathrm{CD}]$ \\
\end{tabular} & HWE P value \\
\hline & & & TT & & $\mathrm{CC}$ & & & \\
\hline Min, 2012 & Korea & $446 / 502$ & $2211 / 232$ & $177 / 219$ & $48 / 51$ & 0.320 & 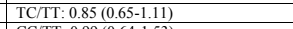 & 0.948 \\
\hline $\begin{array}{l}\text { Zhang, } 2012 \\
\text { Lv , 2013 }\end{array}$ & $\begin{array}{l}\text { China } \\
\text { China }\end{array}$ & $443 / 435$ & $203 / 187$ & $190 / 202$ & $50 / 46$ & 0.337 & \begin{tabular}{|l|l|} 
CC/TT: $0.99(0.64-1.53)$ \\
\end{tabular} & $\begin{array}{l}0.431 \\
<05\end{array}$ \\
\hline $\begin{array}{l}\frac{\mathrm{V}, \mathrm{v}, 2013}{\mathrm{~V} \text { inci, } 2013} \\
\end{array}$ & $\begin{array}{l}C_{\text {China }} \\
\text { Italy }\end{array}$ & $\frac{353 / 340}{160 / 178}$ & $\frac{2353 / 308}{23 / 17}$ & $\frac{64 / 1 / 33}{58 / 75}$ & & $\frac{0.217}{0.306}$ & 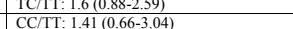 & \\
\hline & & & & & & & 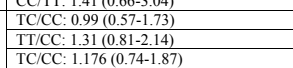 & \\
\hline Overall & & $1402 / 1655$ & & & & & 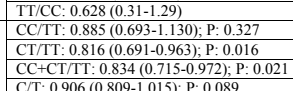 & \\
\hline
\end{tabular}

$\mathrm{OR}=$ odds ratio; $\mathrm{CI}=$ confidence interval; HWE $=$ Hardy-Weinberg equilibrium.

\section{Other miRNA SNPs in CRC}

Our review also identified other miRNA SNPs reported in only one or two investigations to influence CRC risk (Table 7). Owing to the limited number of articles in question, metaanalysis was not performed for these variants. Further studies of these polymorphic sites need to be carried out to explore their roles in CRC.

\begin{tabular}{|c|c|c|c|c|c|c|c|}
\hline \multirow{2}{*}{ Reference (first author) } & \multirow[t]{2}{*}{ Nation } & \multirow{2}{*}{ miRNA SNP ID } & Sample size (cases/ controls) & \multicolumn{3}{|c|}{ Genotype distribution (cases/controls) } & \multirow{2}{*}{ Risk in original publication $[\mathrm{OR}(95 \% \mathrm{Cl})]$} \\
\hline & & & & Homozygous & \begin{tabular}{|c|} 
Heterozygous \\
96166
\end{tabular} & \begin{tabular}{|l} 
Homozygous \\
$19 / 36$
\end{tabular} & \\
\hline $\begin{array}{l}\text { Ryan, } 2012 \\
\text { Gao, } 2013\end{array}$ & $\begin{array}{l}\text { USA } \\
\text { China }\end{array}$ & $\begin{array}{l}\text { hsa-mir-608 } \\
\text { rs4991950 }\end{array}$ & 2457446 & $124 / 231$ & $96 / 166$ & \begin{tabular}{|c|}
$19 / 36$ \\
$28 / 62$ \\
\end{tabular} & $\begin{array}{ll}\text { GC/CC: } 1.28(0.89-1.84) \\
\end{array}$ \\
\hline $\mathrm{Li}, 2013$ & China & $\frac{15411010}{\mathrm{miR}-34 \mathrm{~b} / \mathrm{c}}$ & $244 / 17283$ & $\mathrm{NA}$ & $\frac{144 / 210}{\mathrm{NA}}$ & $\frac{28762}{\mathrm{NA}}$ & 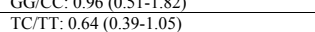 \\
\hline $\mathrm{Oh}, 2014$ & Korea & rs 49938723 & $545 / 428$ & $272 / 216$ & $233 / 171$ & $40 / 41$ & CC/TT: $0.56(0.34-0.91)$ \\
\hline Zhang, 2012 & China & miR-143/145 & $443 / 435$ & $219 / 199$ & $152 / 190$ & $63 / 61$ & $\mathrm{NA}$ \\
\hline & & \begin{tabular}{l|} 
miR-34b/c \\
rs4938723 \\
hsa-miR-605 \\
rs2043556
\end{tabular} & & & & & $\frac{\mathrm{NA}}{\mathrm{NA}}$ \\
\hline
\end{tabular}

miRNA = microRNA; SNP = single nucleotide polymorphism; $\mathrm{OR}=$ odds ratio; $\mathrm{CI}=$ confidence interval; $\mathrm{NA}=$ not applicable.

\section{Study limitations}

Certain limitations to our investigation should be considered. First, inconsistencies were observed between the findings of single studies and our final analysis. In the present study, we concentrated on the effects of miRNA SNPs in the overall human population, finding that certain genotypes may affect cancer risk, while others do not. However, environmental factors may also contribute to oncogenesis. In future, to explore the influence of miRNA SNPs on cancer susceptibility in different environmental backgrounds, we should take such factors into account, and carry out subgroup analysis by population or lifestyle variables. Second, the 
limited number of studies included in our analysis may also have affected its results. Although we included most of the relevant reports published to date, and no fewer than previous metaanalyses performed by other groups, this issue may have introduced bias into our overall analysis. Third, the sample sizes of the datasets used in our investigation ranged from 100 to 1000. However, to confirm our results, more studies with larger sample sizes should be carried out and be incorporated into our analysis to increase its power.

Heterogeneity and publication bias are major concerns in meta-analyses. The former was detected among studies in the overall comparisons for rs11614913 in miR-196a-2 and rs2910164 in miR-146a. However, tests of sensitivity indicated that our results were statistically reliable in each meta-analysis. The omission of any study made no significant difference to the pooled OR. Publication bias was assessed using Begg's funnel plot and the Egger test. None was observed in our examinations of rs11614913 and rs2910164, with the shape of the corresponding funnel plots revealing no obvious asymmetry. Publication bias was not tested for rs3746444 (miR-499), rs895819 (pre-miR-27a), or rs2292832 (miR-149) because of the small number of studies involved.

In this review, we summarized and discussed current knowledge of the role of miRNA SNPs in CRC. Furthermore, meta-analysis was carried out to evaluate associations between the five most frequently studied of these and CRC risk.

rs11614913, rs2910164, and rs3746444 in miR-196a-2, miR-146a, and miR-499, respectively, are frequently reported as being related to this disease. However, in our metaanalysis, no correlation between these three polymorphic sites and CRC risk was established. Population differences may account for this negative result, as one SNP may exert divergent effects on cancer risk in separate populations. The limited number of studies might also explain this finding, and our results should be interpreted with caution. In addition, miRNA SNPs may influence a single gene's function at the molecular level, but when considered together in epidemiological investigations, multiple genes might be affected, resulting in different associations with cancers from a phenotypic perspective.

The polymorphisms rs2292832 in miR-149 and rs895819 in pre-miR-27a were found to be associated with CRC risk in our analysis. Further studies should be carried out to validate this conclusion.

\section{Conflicts of interest}

The authors declare no conflict of interest.

\section{ACKNOWLEDGMENTS}

Research supported by the National Natural Science Foundation of China (\#81302149), the Distinguished Young Scientist of Sichuan University (\#2013SCU04A38), the Science \& Technology Pillar Program of Sichuan Province (\#2014KJT059-\#2014SZ0001), the Ph.D. Program Foundation of Ministry of Education of China (\#20130181120011), the Science \& Technology Project of Henan Province (\#132300410105), and the Ph.D. Scientific Research Foundation of Henan University of Science and Technology (\#09001492).

\section{REFERENCES}

Akkiz H, Bayram S, Bekar A, Akgöllü E, et al. (2011). Genetic variation in the microRNA-499 gene and hepatocellular carcinoma risk in a Turkish population: lack of any association in a case-control study. Asian Pac. J. Cancer Prev. 12: $3107-3112$.

Genetics and Molecular Research 15 (3): gmr.15038478 
Cao Y, Hu J, Fang Y, Chen Q, et al. (2014). Association between a functional variant in microRNA-27a and susceptibility to colorectal cancer in a Chinese Han population. Genet. Mol. Res. 13: 7420-7427. http://dx.doi.org/10.4238/2014. September. 12.8

Chae YS, Kim JG, Lee SJ, Kang BW, et al. (2013). A miR-146a polymorphism (rs2910164) predicts risk of and survival from colorectal cancer. Anticancer Res. 33: 3233-3239.

Chen H, Sun LY, Chen LL, Zheng HQ, et al. (2012). A variant in microRNA-196a2 is not associated with susceptibility to and progression of colorectal cancer in Chinese. Intern. Med. J. 42: e115-e119. http://dx.doi.org/10.1111/j.1445$\underline{5994.2011 .02434 . x}$

Chen W, Zheng R, Zeng H, Zhang S, et al. (2015). Annual report on status of cancer in China, 2011. Chin. J. Cancer Res. 27: 2-12. http://dx.doi.org/10.1186/s40880-015-0001-2

Dikaiakos P, Gazouli M, Rizos S, Zografos G, et al. (2015). Evaluation of genetic variants in miRNAs in patients with colorectal cancer. Cancer Biomark. 15: 157-162.

Du W, Ma X, Kong W, Liu T, et al. (2013). Association between rs11614913 polymorphism in miR-196a2 and colorectal cancer risk: a meta-analysis. Cancer Biomark. 13: 457-464.

Gao LB, Li LJ, Pan XM, Li ZH, et al. (2013). A genetic variant in the promoter region of miR-34b/c is associated with a reduced risk of colorectal cancer. Biol. Chem. 394: 415-420. http://dx.doi.org/10.1515/hsz-2012-0297

Garzon R, Marcucci G and Croce CM (2010). Targeting microRNAs in cancer: rationale, strategies and challenges. Nat. Rev. Drug Discov. 9: 775-789. http://dx.doi.org/10.1038/nrd3179

Gu J, Chen Y, Huang H, Yin L, et al. (2014). Gene module based regulator inference identifying miR-139 as a tumor suppressor in colorectal cancer. Mol. Biosyst. 10: 3249-3254. http://dx.doi.org/10.1039/C4MB00329B

Guo J, Jin M, Zhang M and Chen K (2012). A genetic variant in miR-196a2 increased digestive system cancer risks: a meta-analysis of 15 case-control studies. PLoS One 7: e30585. http://dx.doi.org/10.1371/journal.pone.0030585

Hezova R, Kovarikova A, Bienertova-Vasku J, Sachlova M, et al. (2012). Evaluation of SNPs in miR-196-a2, miR-27a and miR-146a as risk factors of colorectal cancer. World J. Gastroenterol. 18: 2827-2831. http://dx.doi.org/10.3748/ wjg.v18.i22.2827

Hoffman AE, Zheng T, Yi C, Leaderer D, et al. (2009). MicroRNA miR-196a-2 and breast cancer: a genetic and epigenetic association study and functional analysis. Cancer Res. 69: 5970-5977. http://dx.doi.org/10.1158/0008-5472.CAN$\underline{09-0236}$

Hu X, Li L, Shang M, Zhou J, et al. (2014). Association between microRNA genetic variants and susceptibility to colorectal cancer in Chinese population. Tumour Biol. 35: 2151-2156. http://dx.doi.org/10.1007/s13277-013-1285-y

Kida H, Takano Y, Yamamoto K, Mori M, et al. (2014). A single nucleotide polymorphism in fibronectin 1 determines tumor shape in colorectal cancer. Oncol. Rep. 32: 548-552.

Landi D, Gemignani F and Landi S (2012). Role of variations within microRNA-binding sites in cancer. Mutagenesis 27: 205-210. http://dx.doi.org/10.1093/mutage/ger055

Li L, Chen XP and Li YJ (2010). MicroRNA-146a and human disease. Scand. J. Immunol. 71: 227-231. http://dx.doi. org/10.1111/j.1365-3083.2010.02383.X

Li L, Pan X, Li Z, Bai P, et al. (2013). Association between polymorphisms in the promoter region of miR-143/145 and risk of colorectal cancer. Hum. Immunol. 74: 993-997. http://dx.doi.org/10.1016/j.humimm.2013.04.019

Li YJ, Zhang ZY, Mao YY, Jin MJ, et al. (2014). A genetic variant in MiR-146a modifies digestive system cancer risk: a meta-analysis. Asian Pac. J. Cancer Prev. 15: 145-150. http://dx.doi.org/10.7314/APJCP.2014.15.1.145

Lv M, Dong W, Li L, Zhang L, et al. (2013). Association between genetic variants in pre-miRNA and colorectal cancer risk in a Chinese population. J. Cancer Res. Clin. Oncol. 139: 1405-1410. http://dx.doi.org/10.1007/s00432-013$\underline{1456-7}$

Ma L, Zhu L, Gu D, Chu H, et al. (2013). A genetic variant in miR-146a modifies colorectal cancer susceptibility in a Chinese population. Arch. Toxicol. 87: 825-833. http://dx.doi.org/10.1007/s00204-012-1004-2

Mao Y, Li Y, Jing F, Cai S, et al. (2014). Association of a genetic variant in microRNA-146a with risk of colorectal cancer: a population-based case-control study. Tumour Biol. 35: 6961-6967. http://dx.doi.org/10.1007/s13277-014-1916-y

Min KT, Kim JW, Jeon YJ, Jang MJ, et al. (2012). Association of the miR-146aC>G, 149C>T, 196a2C > T, and 499A >G polymorphisms with colorectal cancer in the Korean population. Mol. Carcinog. 51 (Suppl 1): E65-E73. http:// dx.doi.org/10.1002/mc. 21849

Oh J, Kim JW, Lee BE, Jang MJ, et al. (2014). Polymorphisms of the pri-miR-34b/c promoter and TP53 codon 72 are associated with risk of colorectal cancer. Oncol. Rep. 31: 995-1002.

Pardini B, Rosa F, Naccarati A, Vymetalkova V, et al. (2015). Polymorphisms in microRNA genes as predictors of clinical outcomes in colorectal cancer patients. Carcinogenesis 36: 82-86. http://dx.doi.org/10.1093/carcin/bgu224

Parlayan C, Ikeda S, Sato N, Sawabe M, et al. (2014). Association analysis of single nucleotide polymorphisms in miR-

Genetics and Molecular Research 15 (3): gmr.15038478 
146a and miR-196a2 on the prevalence of cancer in elderly Japanese: a case-control study. Asian Pac. J. Cancer Prev. 15: 2101-2107. http://dx.doi.org/10.7314/APJCP.2014.15.5.2101

Ryan BM, Robles AI and Harris CC (2010). Genetic variation in microRNA networks: the implications for cancer research. Nat. Rev. Cancer 10: 389-402. http://dx.doi.org/10.1038/nrc2867

Ryan BM, McClary AC, Valeri N, Robinson D, et al. (2012). rs4919510 in hsa-mir-608 is associated with outcome but not risk of colorectal cancer. PLoS One 7: e36306. http://dx.doi.org/10.1371/journal.pone.0036306

Schetter AJ and Harris CC (2011). Alterations of microRNAs contribute to colon carcinogenesis. Semin. Oncol. 38: 734742. http://dx.doi.org/10.1053/j.seminoncol.2011.08.009

Torre LA, Bray F, Siegel RL, Ferlay J, et al. (2015). Global cancer statistics, 2012. CA Cancer J. Clin. 65: 87-108. http:// dx.doi.org/10.3322/caac. 21262

Vinci S, Gelmini S, Mancini I, Malentacchi F, et al. (2013). Genetic and epigenetic factors in regulation of microRNA in colorectal cancers. Methods 59: 138-146. http://dx.doi.org/10.1016/j.ymeth.2012.09.002

Wang FJ, Ding Y, Mao YY, Jing FY, et al. (2014a). Associations between hsa-miR-603 polymorphism, lifestyle-related factors and colorectal cancer risk. Cancer Biomark. 14: 225-231.

Wang Z, Sun X, Wang Y, Liu X, et al. (2014b). Association between miR-27a genetic variants and susceptibility to colorectal cancer. Diagn. Pathol. 9: 146. http://dx.doi.org/10.1186/1746-1596-9-146

$\mathrm{Wu}$ X, Xu X, Li S, Wu S, et al. (2015). Identification and validation of potential biomarkers for the detection of dysregulated microRNA by qPCR in patients with colorectal adenocarcinoma. PLoS One 10: e120024. http://dx.doi.org/10.1371/ journal.pone. 0120024

Xie WQ, Tan SY and Wang XF (2014). Effect of a common genetic variant microRNA-146a rs2910164 on colorectal cancer: a meta-analysis. J. Dig. Dis. 15: 647-653. http://dx.doi.org/10.1111/1751-2980.12201

Yong FL, Law CW and Wang CW (2013). Potentiality of a triple microRNA classifier: miR-193a-3p, miR-23a and miR338-5p for early detection of colorectal cancer. BMC Cancer 13: 280. http://dx.doi.org/10.1186/1471-2407-13-280

Zhan JF, Chen LH, Chen ZX, Yuan YW, et al. (2011). A functional variant in microRNA-196a2 is associated with susceptibility of colorectal cancer in a Chinese population. Arch. Med. Res. 42: 144-148. http://dx.doi.org/10.1016/j. arcmed.2011.04.001

Zhang MW, Jin MJ, Yu YX, Zhang SC, et al. (2012). Associations of lifestyle-related factors, hsa-miR-149 and hsamiR-605 gene polymorphisms with gastrointestinal cancer risk. Mol. Carcinog. 51 (Suppl 1): E21-E31. http://dx.doi. org/10.1002/mc. 20863

Zhi ML, Liu ZJ, Yi XY, Zhang LJ, et al. (2015). Diagnostic performance of microRNA-29a for colorectal cancer: a metaanalysis. Genet. Mol. Res. 14: 18018-18025. http://dx.doi.org/10.4238/2015.December.22.28

Zhu L, Chu H, Gu D, Ma L, et al. (2012). A functional polymorphism in miRNA-196a2 is associated with colorectal cancer risk in a Chinese population. DNA Cell Biol. 31: 350-354. http://dx.doi.org/10.1089/dna.2011.1348

\section{Supplementary material}

Table S1. Assessment of the quality of the studies included in our meta-analysis.

Genetics and Molecular Research 15 (3): gmr.15038478 